\title{
Building a Regional Community with IT: The Practical IT Education in My Case
}

\author{
Yoshinori Fujio \\ Prefectural University of Kumamoto, Kumamoto, Japan
}

\author{
fujio@pu-kumamoto.ac.jp
}

\begin{abstract}
In Japan, e-Japan planning (Nihon Keizai Shinbun Inc., 2002) is actively moving forward and the infrastructure for a computerized society is being worked on. But, at present it is fumbling and groping to find good ways for a regional community to use IT. This university's administration department (Administration Science), with information technology (IT) as its base, is pursuing increasing the effectiveness of public administration and management commonality. Namely, that public administration, companies, the public and NPO co-operate with the aim of realizing a "Citizen Centered Society" and an "Active Regional Community."
\end{abstract}

This paper introduces "Research into How Building a Regional Community with IT Can be done" (Philosophy) and four actual examples of "Specifically using IT for Trial Information Systems" (Practical Science) implemented by the department's $4^{\text {th }}$ year student's graduation research in accordance with the complementary theme "Regional Close-contact Information Systems". Through this practical research, the students were able to understand the methods for planning and building a system to use IT in a regional community. The task from here on is how to expand the functions in order to deal with new technology and effectively use the system.

Keywords: Multidiscipline, Regional community, IT system design, E-business, Undergraduate research

\section{Introduction}

In Japan, the Information System course curriculum (Information System Committee, 2001) is determined based on CC2001 (CC-2001 Steering Committee, 2001) decided and promulgated by the ACM and IEEE-CS Joint Curriculum Task Force. This curriculum is for students that are specializing in information systems. In IT education, it is necessary to introduce social science and information science, but there are few that go to the extent of "Teaching E-Commerce" (Dhamija, Heller, Hoffman, 1999) introduced in the practical examples.

This paper relates a practical educational example of how students studying social science use an information system and a method of constructing an information system. After studying a lecture course (Fujio, 2000) on information system planning, they construct a test system using basic technology (Fujio,

Material published as part of these proceedings, either on-line or in print, is copyrighted by Informing Science. Permission to make digital or paper copy of part or all of these works for personal or classroom use is granted without fee provided that the copies are not made or distributed for profit or commercial advantage AND that copies 1) bear this notice in full and 2) give the full citation on the first page. It is permissible to abstract these works so long as credit is given. To copy in all other cases or to republish or to post on a server or to redistribute to lists requires specific permission from the publisher at Publisher@InformingScience.org
2000; Fujio, 2001; Fujio, 2002), namely HTML, Java Language and Access.

Research is implemented with a Spiral Model. One cycle of research is done in one year, and the first cycle second cycle and third cycle are planned. The first cycle was the implemented development system adjustment stage in 2001. Creation of this paper's trial system in 2002 was

Paper Accepted as a Short Paper 
the second stage, and was developed from the first cycle. Papers are written and specification creation is done at the end of each cycle to compile the research and hand over the research and technology to the next cycle. Also, at the start of a cycle, a research plan is created using the papers from the previous cycle as a reference. According to the Spiral Model, the system functions and operation can be enlarged every time a year goes by.

\section{Outline of Four Actual Examples}

\section{Research Titles}

The goal of the research is to do theoretical research into ways to actualize a "Citizen Centered Society" and an "Active Regional Community," and research trials of information systems through IT, and information systems construction methods.

The specific individual research theme examples are as follow.

1. Government officials and the public communication: "Citizen Participation in the e- Municipality."

2. Detailed warehouse management using a mobile terminal: "Distribution and Product Management by Mobile Phone."

3. Shops for the regional community's needs: "The Depopulated Area Shopping Mall."

4. The farmer and consumer community: "Promoting NPO, nonprofit organization, Group computerization."

\section{Elements of Technique and Equipment}

The technology components used are the basic technology components used when constructing a Web system. Namely, the entire information system schematic (class diagram, sequence diagram, state change diagram etc.) is written in UML. The system is constructed in a 3 layer structure. The presentation layer that does the information request and display is designed in HTML, the functionary layer that administers information and connects is designed in Java language servlet (Callay, 1999) and JSP (Pekowsky, 2000), and the data layer that stores and provides information is organized in the relational database Access.

The equipment used was a desktop PC (Price about \$2,000). The PC hardware was a Pentium 4 $(1.6 \mathrm{GHz}), 256 \mathrm{Mbyte}$ of RAM and a 80GB HD. The software was Windows XP professional for the OS, and Access for the database was the standard for the proto type system. The development and execution system used JDK: Java 2 SDK/ Standard Edition 1.3.1, Web Server: Apache, Servlet and Contemn:

Tomcat 4 .

\section{Specific Research}

This relates the research summary through the background applicable to the research, references, field surveys, and the structure and running of the trial system.

\section{Citizen Participation in the e-Municipality}

In one e-Japan strategic policy theme, "Computerization of Government Administration and Public Fields." is brought up. It considers practical use of IT in local government, and toward that goal admin- 
istrative clarity, public disclosure of information, creating a structure for the public to participate in local government, and making its administration more effective and lean.

In contrast to the increasingly severe financial environment of municipalities, the values of the public and what they need from local government are becoming ever more diverse. (See Figure 1 for the interaction between a citizen and a municipality.)

In Japan the status of the e-municipality is:

1. Nimi City in Okayama prefecture implemented "e-voting" (The Association of Electric Voting System, 2002) on June 23, 2003.

2. Fujisawa City in Kanagawa prefecture "e-assembly" (Fujisawa City, 2002) aiming for the formation of a citizen participation community will start operation in March 2003.

3. "e-talk Sapporo" (Sapporo, 2002) was established in Sapporo City, Hokkaido as a window between citizens and officials.

Based on the present status, to understand the diverse needs of the residents, and as a means of reflecting the people's opinion in government policy drafts, a 'Web-based Questionnaire System" was tested. There is expectation that using the questionnaire survey system will lead toward movement froman authoritarian society to a society where government officials and the public are partners. This system is centered on a server that stores the questionnaire content input by the public with a client side Web browser, and aggregates and analysis it. A servlet does the server side processing.

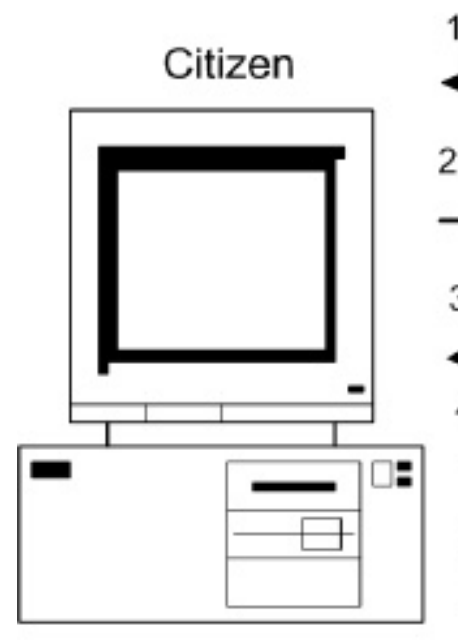

\section{1) Making public of Public works' project plan}

2) Opinion filling in

3) Answer result \& Reviewed policy

4) Opinion about Reviewed policy

5) Making public of Final examination result

Figure 1: The interaction between a citizen and a municipality

The following is a procedure of connection with database, search to it and getting results from it using JSP.

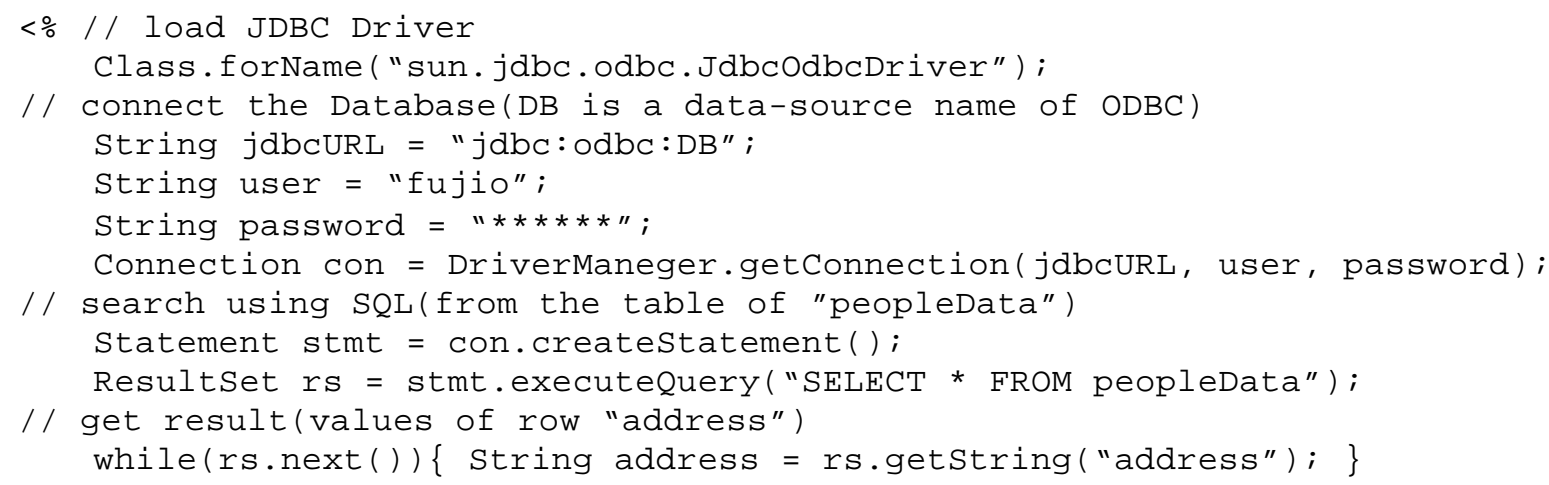




\section{// disconnect \\ stm.close (); \\ con.close (); $\frac{\circ}{0}>$}

The decrease in the percentage of people voting in elections and supporting political parties because of distrust of politicians, political parties, the Diet and administration is a problem. And, the distance between politics and citizens continues to increase. What can shrink this distance is e-democracy. The Internet increases the opportunity and provides a way for the people to participate in politics, and realizes a democratic society where the people's opinion is more reflected in politics and the quality of administration is higher.

\section{Distribution and Product Management by Mobile Phone}

Internet use has passed 50\% due to portability of the mobile phone, and the addition of NTT Docomo "i-Mode" (Internet access ), J-Phone J-SKY and au Ezweb etc. to the call function. Mobile phones have spread with energy enough to surpass the number of fixed phones.

In Japan there are distribution and credit systems using "i-convenience" (Matsushita Electric Industrial Co., Ltd., 2002) and i-Mode in convenience stores. CDs, DVDs, videos, books, lodging reservations are sold through i-Mode. In the future, moving images, agent services, and Bluetooth and infrared transmission are planned. The security system "View Web" (HITACHI Security Service, 2002), is a system that lets you check the images filmed by a security camera in places such as a nursery school, senior facility, store or office, workplace machine room from another location with a mobile phone. For distribution systems, "e's" (Sagawa Express Co., Ltd., 2002), there is the system that connects the distribution center and the driver in real time using mobile phones.

We researched distribution systems and warehouse management using the features of the mobile phone, used applets and servlets on one part of a warehouse management system, and ran a trial. Because the hardware functionality of a mobile phone is limited, we used CLDC as the framework even in J2ME which is one function set of Sun Microsystems programming language "Java2", organized with the functions for integrated devices such as home electronics, portable information terminals (PDA) and

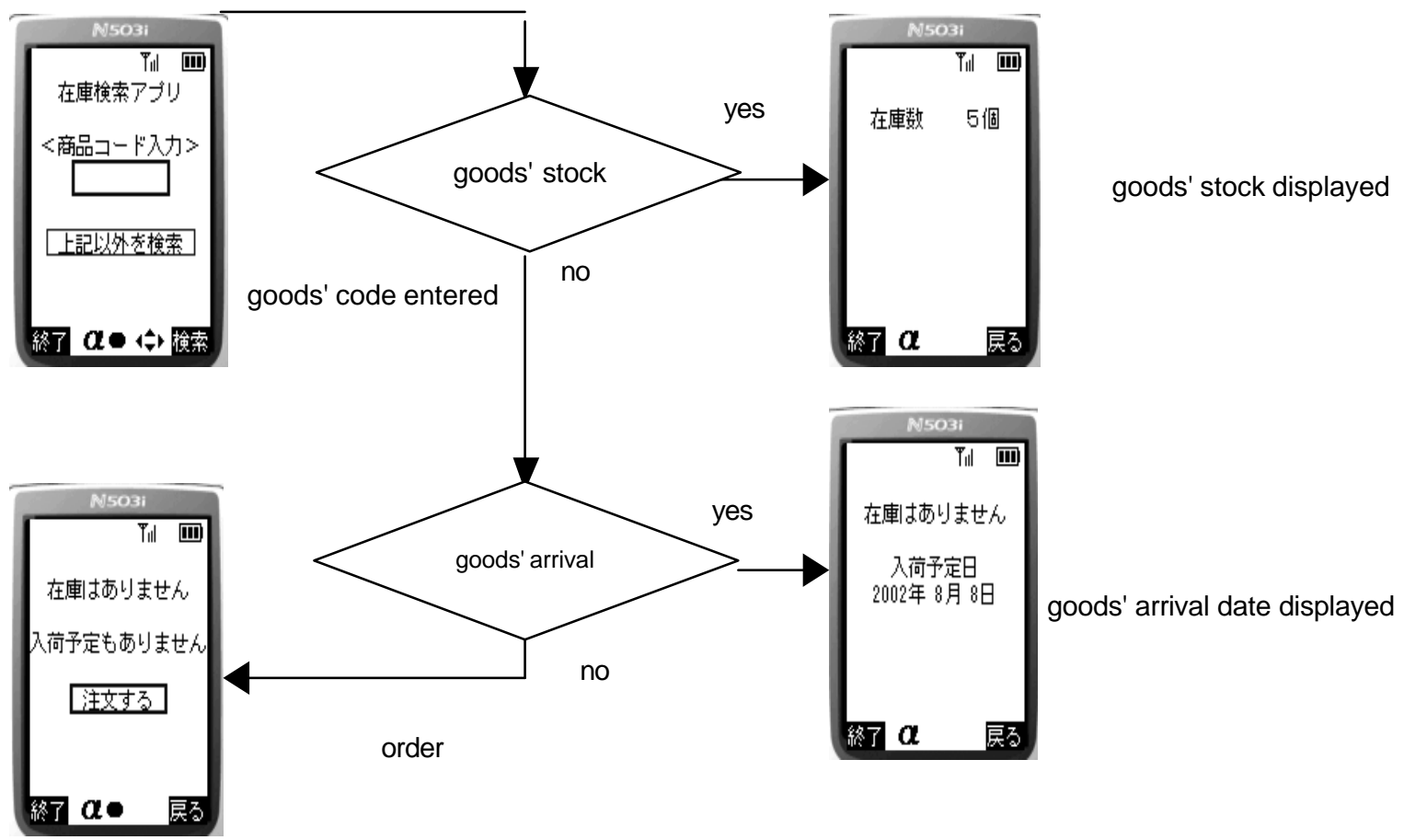

Figure 2: The input screen of stock management using the mobile phone 
mobile phones. The basic Java API used by the mobile phone is used in this CLDC. Also, Sun Microsystems, for its detailed mobile phone specification, has defined MIDP which is used by J-Phone and au for mobile phones as the mobile phone standard profile, but NTT Docomo uses its independently developed Doja (NTTdocomo, 2002) profile.

The stock management input screen by mobile phone is as follows (see Figure 2).
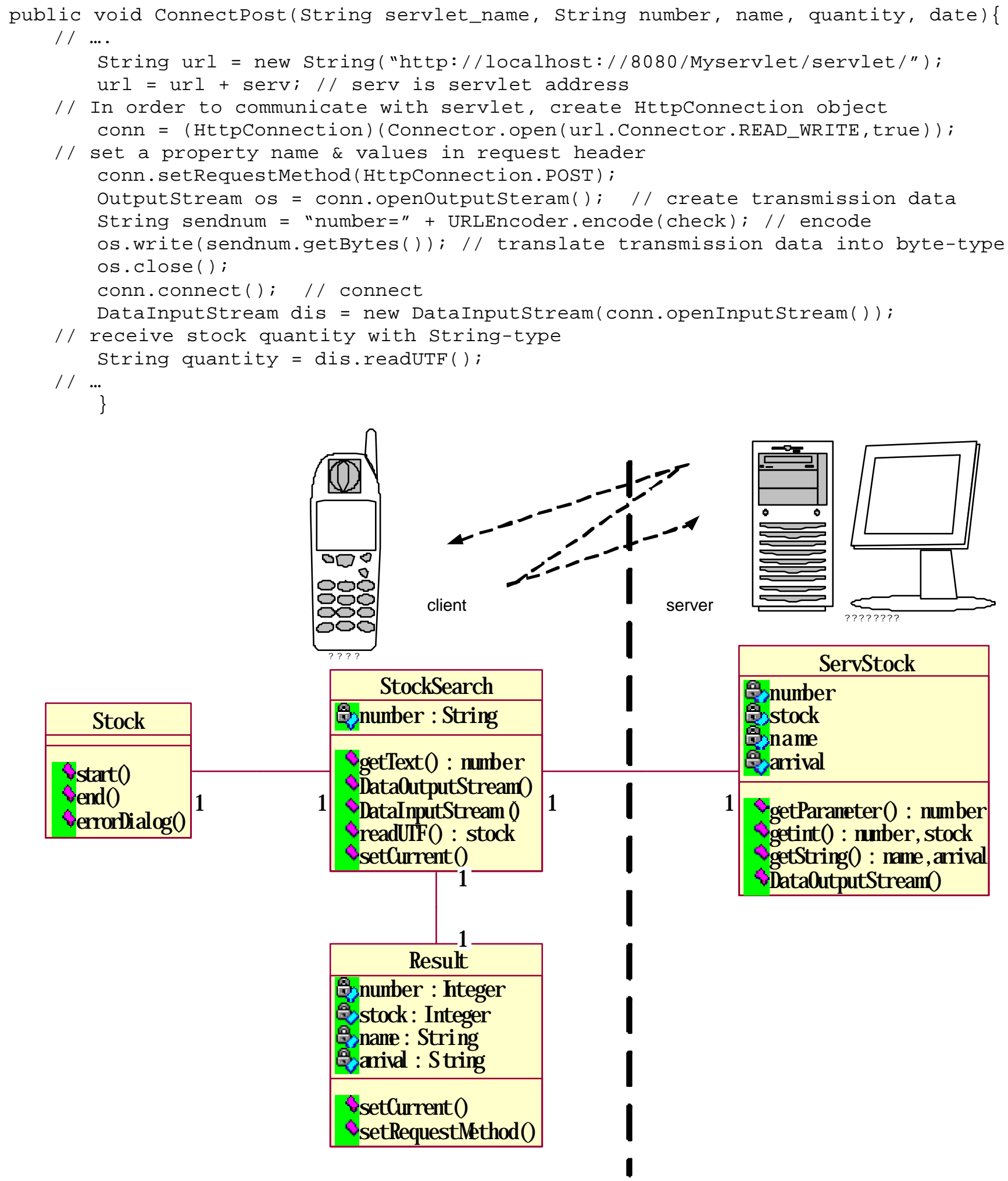

Figure 3: The class diagram 
The stock, stock search and result classes in the mobile phone, and the stock processing class in the server co-operate and process. Figure 3 shows the stock search that does transmission between the mobile phone and the server.

\section{The Regional Shopping Mall}

In recent years, the retail sector has declined because of weak consumer activity due to the serious economic situation. In particular, small-scale retail stores have shown a rapid decline in yearly sales, while large-scale retail stores did have a rapid increase in sales and were in good shape. However, since January of 2001, the large scale retail stores "Sogo" and "Mycal" have gone bankrupt, and even in Kumamoto prefecture, "Kotobukiya" and "Nikonikodo" have failed. "Will Small Scale Retail Stores Survive" is a more serious problem than the revival of large scale retail stores.

In regional (rural) communities, depopulation and aging are continuing and create a problem for local economic development. We did research using IT that we thought could solve the problem with the aim of realizing an easy-to-live-in regional community. In the public forum, " The Kumamoto Present Economic Condition" the most frequent comment about the shopping district was, "Does not attract consumers" (Attraction points are different among people, for example, low price, a bountiful and high quality product assortment and service with high customer satisfaction.) These can be strengthened if the "Mobility Based on a Local partnership" and "Mobility that Corresponds to Delivery and Consumer Needs" is made use of. The test system was constructed from this point of view.

The system is realized using the following procedure.

(1)The local stores are organized, and formed into a e-mall using the Internet.

(2)Customer orders are taken by the sales staff by TEL, FAX or Internet at the Shopping Mall common sales counter.

(3)The sales staff buy the Shopping Mall merchandise, collect it, and deliver it to the home. For ease-of-use by the elderly, virtual Shopping Mall functions are added to actual Shopping Mall functions.

The shopping site was structured with user registration, product search, product purchase, confirmation and cancellation functions, and constructed to connect with Access and JSP. The shopping site screen transition is shown in Figure 4.

There are many advantages for a small-scale retail store to introduce a shopping site. They can be a delivery service at the desired time for the elderly or working couples, a time service where the price changes according to the time, showing the details of the product and reducing advertising costs, and customer and product management using a database. However, the local people's independent activity is desired for the delivery and system operation.

\section{Promoting NPO Group Computerization}

Problems related to the quality of human life such as environmental and social welfare cannot be adequately solves by only commercial organizations that have making a profit as their first priority. The NPO, which may be able to solve these kinds of problem, is non-profit and by undertaking activities with the goal of the good of the community, carries the role of easing the market competition barrier.

Specifically, we supported one Kumamoto NPO group, the "The Kumamoto Organic Certification Association" in its computerization. Many of the NPO members have other jobs in addition to their NPO activities. For that reason it is normal for them to be in different locations. So to speak, a dispersed type business structure. 


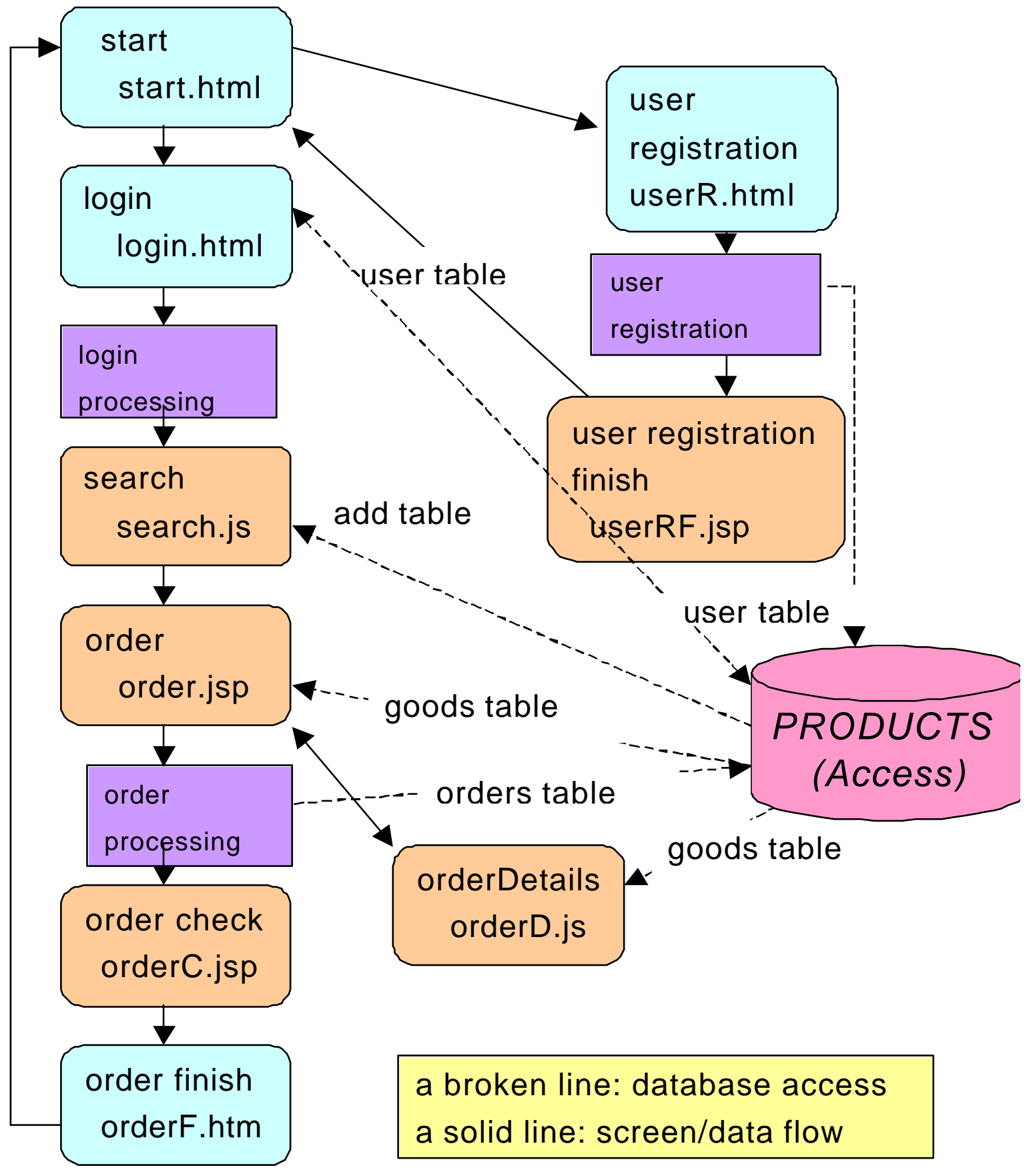

Figure 4: The screen transition

Also, the Internet that began to spread at the same time as the NPO is highly compatible with a dispersed type business structure. Therefore we promoted computerization that used the Internet.

The trial system was the NPO "The Kumamoto Organic Certification Association" membership list and homepage creation (The Kumamoto Organic Certification Association, 2001) (Figure 5).

The homepage content items "Recent Items of Note" are recent enterprise reports interspersed with pictures and published. "Kumoyuken Certification System" is organic certification work content and fees. "The Kumamoto Organic Certification Association" is the foundation details and object published as a "Prospectus" and "Business Plan Report." The "Participant Group" and "Membership drive and enrollment guide" are items that work to create membership drives to spread "Organic (farming)". 


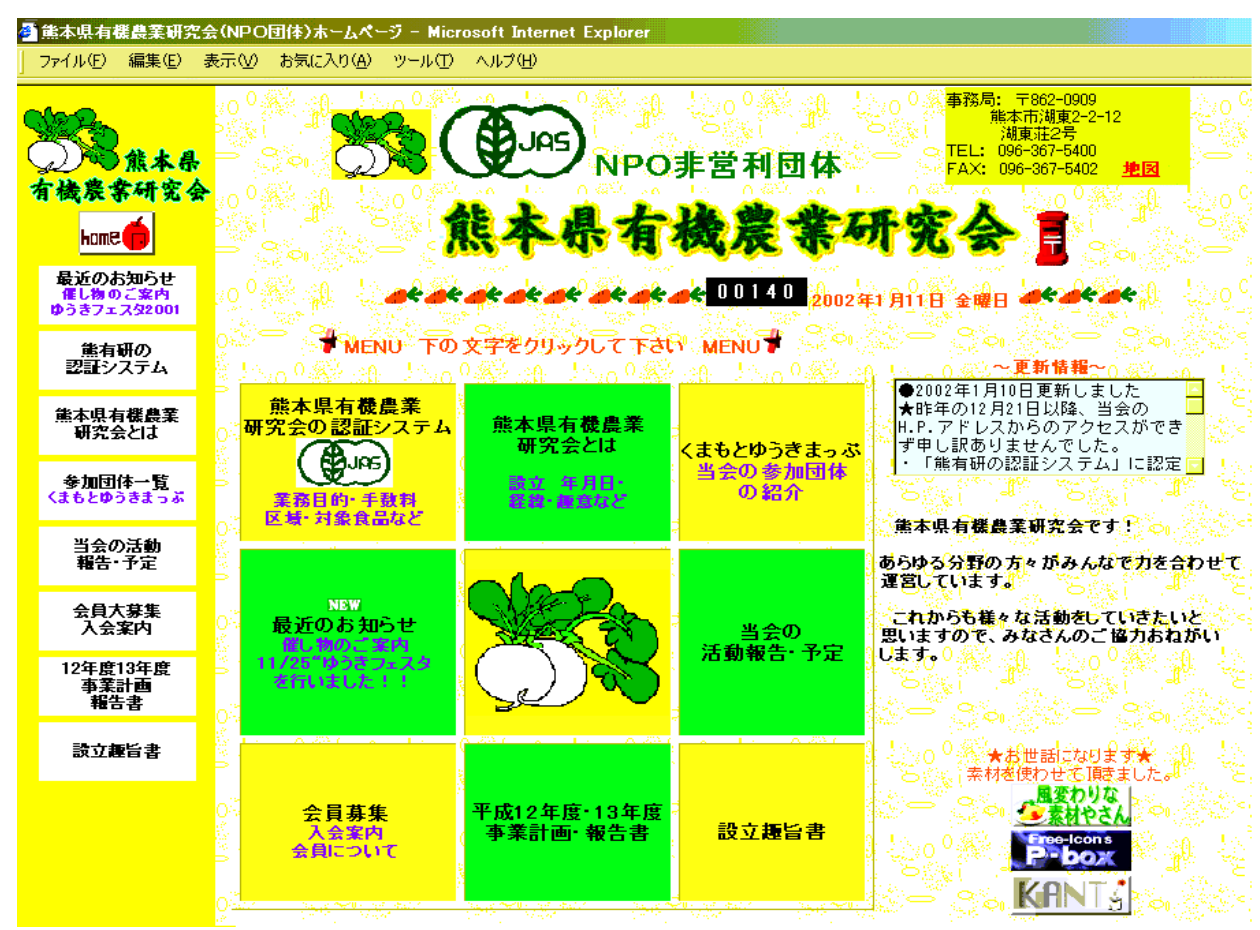

Figure 5: The home page of the Kumamoto Organic Certification Association

\section{Education Results}

When they had finished their research, the students were given a questionnaire to test their level of understanding of IT. The students were divided in groups with a fundamental knowledge and a strong desire to study IT (H.L. Group; the high level group 5 students), and the students with insufficient knowledge and a weak desire to study (L.L. Group; the low level group 3 students), and the results were organized. The self-evaluated results are as follows.

The horizontal axis classifies the knowledge category (Lethbridge, 2000). The vertical axis shows the amount of knowledge.

0: Doesn't know anything

1: Knows a little

2: Basic knowledge

3: Knowledge is adequate to use

4: Has learned a lot

5: Has learned in depth and is an expert

The H.L. Group did reference survey and created a test system. The L.L. Group organized their research with only reference survey.

The results shown in Figure 6 are multi-discipline understanding of the "Management and Information Connection," "How Advance Research" required to do research, and "How to Write a Thesis" etc., that both the H.L. Group and L.L. Group reached a high enough level to use their knowledge.

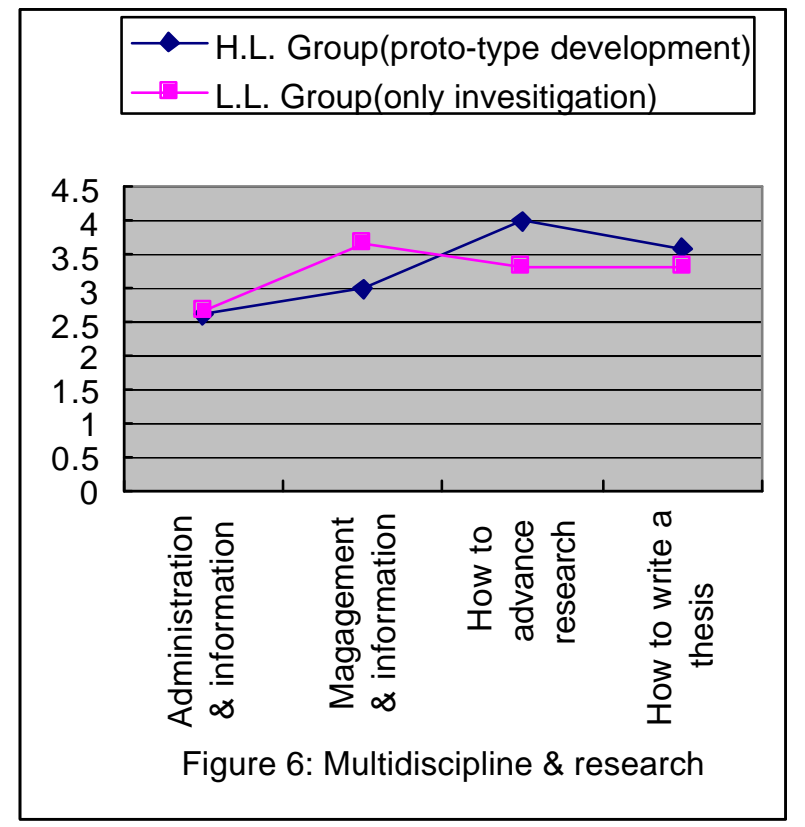


In Figure 7, concerning the system development methodology, H.L. Group was learned in the process of constructing the test system. However the L.L. Group that did not have this experience did not progress past basic knowledge.

Also, in Figure 8, concerning the user interface that is the system architecture, the H.L. Group learned a lot from the planning process. Self-confidence could be seen in the presentation that is necessary as a SE skill. I think that students with goal awareness, namely having the intent to construct the information system required to fix the object system's problem points and an attitude of digging into the lectures and research can achieve a high level of education results.
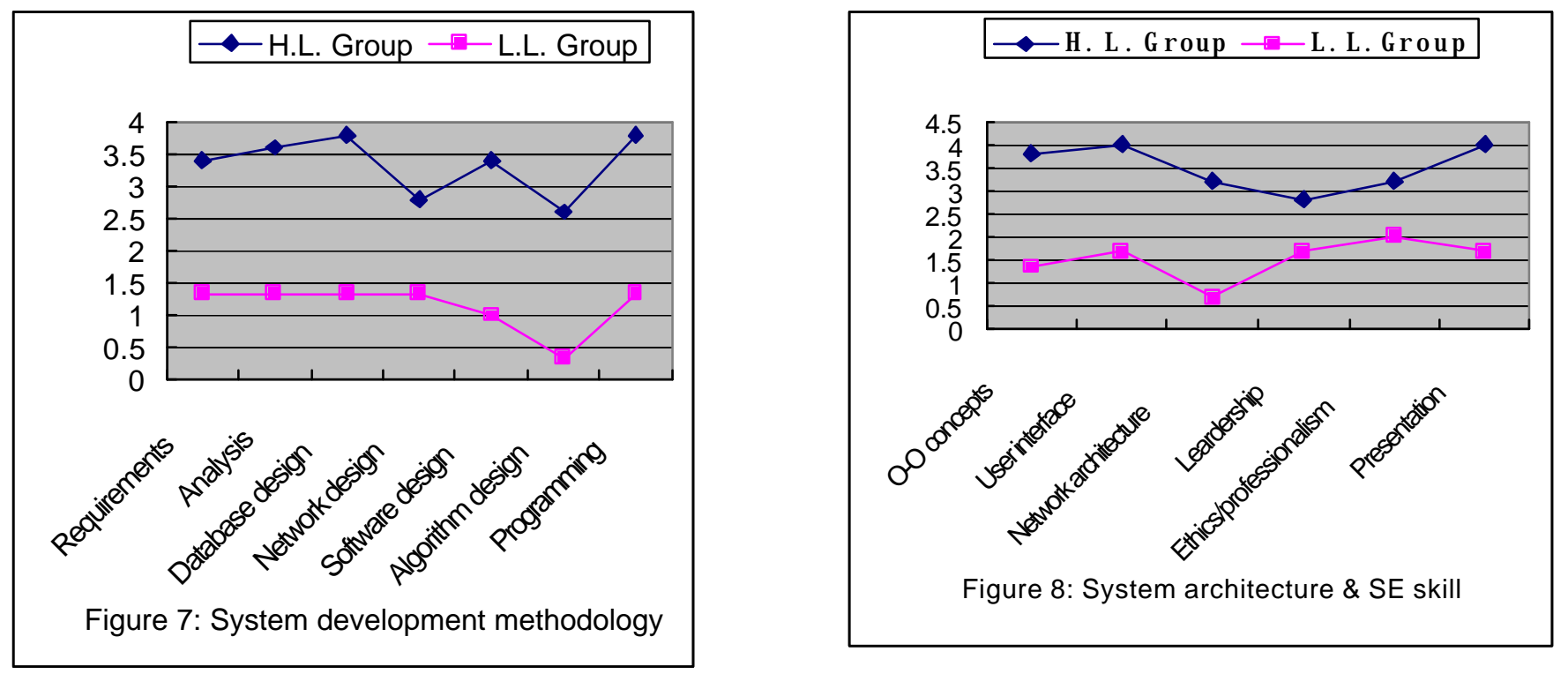

\section{Conclusion}

In the following $3^{\text {rd }}$ cycle, we plan to give the students that take over understanding of the existing development system and design technology and increase the user interface functions. Use the increasingly highly functional ubiquitous mobile phone and increase mobility. Also, we plan increase the functions by making e-government or e-commerce applicable to the presentation layer with XML, and by designing a system that uses Java Beans or Enterprise Java Beans components (Fujio, 2002) that can be reused in the functional layer. Also, we plan to make an object oriented database applicable in the data layer, and tackle adapting to progress in the technology that builds the system and social changes.

To solve the problem points that occur in the regional community, it is necessary to search for a information system that will have roots in the regional community. To do this, it is a prerequisite to analyze the regional community's problem points, and have knowledge of information systems and their technological elements. Toward this, in IT education, lectures, practice and research that that unites with social science and information science is effective.

\section{Acknowledgements}

Eriko Kakita, "Citizen Participation in the e-Municipality," Kosuke Nishimura, "Distribution and Product Management by Mobile Phone," Akira Sonoki, "The Regional Shopping Mall," and Noriko Uehata, "Promoting NPO Groups Computerization" cited to introduce the basic content are the research results of the administration department's research results collected after the $4^{\text {th }}$ year. 


\section{References}

Callay, D.R. (1999). Inside servlets. Reading, MA: Addison Wesley.

CC-2001 Steering Committee. (2001). Retrieved Dec. 8, 2002 from http://www.computer.org/education/cc2001/final/

Dhamija, R., Heller, R., \& Hoffman, L. (1999). Teaching E-Commerce. Communications of the ACM, Vol.42, No.9, 50-55.

Fujio, Y. (2000). Information system design of undergraduate education. Proceedings of SITE 2000, Society for InformatioTechnology \& Teacher Education International Conference, 359-364.

Fujio, Y. (2000). Information \& computer science education for departments of social science(A second look). Administration, Vol.6, No.2 -3, Prefectural Un iversity of Kumamoto, Kumamoto, Japan, 1-12.

Fujio, Y. (2001). Information \& computer science education for departments of social science(A third look). Administration, Vol.7, No.1-2, Prefectural University of Kumamoto, Kumamoto, Japan, 209-223.

Fujio, Y. (2002). Information \& computer science education for departments of social science(A fourth look). Administration, Vol.8, No.3-4, Prefectural University of Ku mamoto, Kumamoto, Japan, 201-213.

Fujio, Y. (2002). Education of overall it system design. 2002 Proceedings Informing Science + IT Education Conference, 507-512.

Fujisawa City. (2002). Citizen meting room of Fujisawa city. Retrieved December, 2002 from http://www.city.fujisawa.kanagawa.jp/ denshi/

HITACHI Security Service. (2002). Retrieved Dec. 4, 2002 from http://www.asf.ne.jp/hitachi-ss/default.asp

Information Systems Committee. (2001). Information Systems Curriculum. Proceedings Accreditation IPSJ Symposium, $37-40$.

Lethbridge, Timothy C. (2000). What knowledge is important to a software professional? Computer, Vol.33, No.5, IEEE Computer Society, 44-50.

Matsushita Electric Industrial Co., Ltd. (2002) . Retrieved Dec. 4, 2002 from the http://www.matsushita.co.jp/

Nihon Keizai Shinbun Inc. (2002). The strategic conference on e-government. Retrieved Nov. 8, 2002 from http://www.nikkei.co.jp/events/egov/s top.html

NTTDocomo. (2002). Retrieved Dec. 4, 2002 from http://www.nttdocomo.co.jp/mc-user/i/java/index.html

Pekowsky, L. (2000). Java server pages. Reading, MA: Addison Wesley.

Sagawa Express Co., Ltd. (2002). Retrieved Dec. 4, 2002 from http://www.sagawa-exp.co.jp/index-j.html

Sapporo City. (2002).e-talk Sapporo. Retrieved December, 2002 from http://infommunity.city.sapporo.jp/

The Association of Electronic Voting Systems. (2002). Retrieved December, 2002 from http://www.evs-j.com/

The Kumamoto Organic Certification Association. (2001). Retrieved 2001 from http://www.h3.dion.ne.jp/ k-yuken/

\section{Biography}

Yoshinori Fujio is a professor at Prefectural University of Kumamoto, where he teaches information system development, software design and web related courses. Professor Fujio has authored papers on the Information \& Computer Science Education, CASE and 4 books on the subject of Information Processing Engineering. 